OPEN ACCESS

Edited by:

Xiangming Zhou,

Brunel University London,

United Kingdom

Reviewed by:

Zhigang Zhang,

Chongqing University, China

Lili Kan,

University of Shanghai for Science and

Technology, China

*Correspondence:

$\mathrm{LiMi}$

Limivip@163.com

Yang Qi

yangq8327@gmail.com

Specialty section:

This article was submitted to

Structural Materials,

a section of the journal

Frontiers in Materials

Received: 08 November 2021

Accepted: 22 November 2021

Published: 20 December 2021

Citation:

Jiangtao Y, Fangming J, Qiong X, Qi Y and Mi L (2021) Mechanical and Self-

Healing Performances of Crumb

Rubber Modified High-Strength

Engineered Cementitious Composites.

Front. Mater. 8:811110.

doi: 10.3389/fmats.2021.811110

\section{Mechanical and Self-Healing Performances of Crumb Rubber Modified High-Strength Engineered Cementitious Composites}

\author{
Yu Jiangtao ${ }^{1,2}$, Jiang Fangming ${ }^{2}$, Xing Qiong ${ }^{1}$, Yang $\mathrm{Qi}^{3 *}$ and $\mathrm{Li} \mathrm{Mi}^{4 *}$ \\ ${ }^{1}$ School of Civil Engineering, Architecture and Environment, Hubei University of Technology, Wuhan, China, ${ }^{2}$ College of Civil \\ Engineering, Tongji University, Shanghai, China, ${ }^{3}$ Qinghai Transportation Planning and Design Research Institute Co., Ltd., Xining, \\ China, ${ }^{4}$ Shanghai Tiangu Housing Inspection Company, Ltd., Shanghai, China
}

High-strength engineered cementitious composite (HS-ECC) reinforced with polyethylene (PE) fiber characterizes wider crack widths than the conventional polyvinyl alcohol fiberreinforced ECC (PVA-ECC), weakening the self-healing potential of HS-ECC. The properties of HS-ECC are tailored by introducing crumb rubber (CR), as artificial flaws can lower the matrix toughness and the crack width, leading to an enhanced self-healing potential of HS-ECC. In this study, CR is used to entirely replace silica sand (SS) with three equivalent aggregate-to-binder ratios of 0.2, 0.4, and 0.6, and two CR particle sizes (i.e., CR1 and CR2) are also considered to investigate the effects on density, compressive properties, and tensile performances of HS-ECC. Although CR substitution of SS influences adversely the mechanical strengths of HS-ECC, it can reduce the HS-ECC matrix fracture toughness, activate more microcracks, and reduce the crack width. Moreover, CR-modified HS-ECC specimens featuring the smallest crack width were preloaded to three specific strain levels, including $0.5 \%, 1.0 \%$, and $2.0 \%$, and then experienced wet-dry conditioning to exhibit effective mechanical and non-mechanical property recovery. The further hydration of binder materials enhances the interfacial bond stress and thus retains the mechanical performances of self-healed HS-ECC, which is expected to improve the practical application and benefit the sustainability of HS-ECC.

Keywords: high-strength engineered cementitious composite, lightweight, crumb rubber, self-healing, tensile properties, sustainability

\section{INTRODUCTION}

Concrete, as the most extensively used building material in the world featuring intrinsic brittleness, is prone to cracking during its service life, which negatively impacts its mechanical performance and leads to potential safety risks to infrastructure. The presence of cracks simultaneously offers pathways for an aggressive agent to penetrate through and causes steel bar corrosion and concrete erosion, which lower the durability and service life of a concrete structure and increase maintenance costs, making concrete infrastructure unsustainable. Therefore, a concrete material that has self-healing capability at cracked locations is highly desirable.

Previous research has identified the required conditions for self-healing in concrete materials, including the presence of specific chemical components such as unhydrated cement grains (Reinhardt and Jooss, 2003), exposure to various environmental conditions (i.e., underwater 
immersion and cyclic wet-dry exposures) (Jacobsen et al., 1996; Edvardsen, 1999), and small crack widths (Jacobsen et al., 1996; Reinhardt and Jooss, 2003). The first two criteria can be easily satisfied, while the third criterion requiring the crack width below $150 \mu \mathrm{m}$ and preferably below $50 \mu \mathrm{m}$ is the most challenging in the design of self-healing concrete materials (Jacobsen et al., 1996; Aldea et al., 2000).

Engineered cementitious composite (ECC) is an outstanding high-performance fiber-reinforced concrete whose characteristics are systematically tailored according to the micromechanics. ECC exhibits well-distributed microcracks and tensile strain capacity of above $3 \%$ with a fiber volume fraction of no more than $2 \%$. The crack width of polyvinyl alcohol (PVA) fiber-reinforced ECC (PVA-ECC) usually stabilizes at approximately $60 \mu \mathrm{m}$ at the loading stage. The tiny crack of PVA-ECC as an intrinsic material property enables its self-healing capability in different environmental conditions (Yang et al., 2009; Kan and Shi, 2012; Zhang et al., 2014; Zhang and Zhang, 2017; Li et al., 2020; Dong et al. 2021; Yu et al., 2021). Thus, the long-term ductility and durability of PVA-ECC after cracking can be improved by the achievement of self-healing capability, resulting in a sustainable building material. However, the tensile strength of PVA-ECC falls in the range of 3-6 MPa with a compressive strength of less than $60 \mathrm{MPa}$ (Reinhardt and Jooss, 2003; Yu et al., 2017), which are lower and may hinder its application in practical engineering.

High-strength ECC (HS-ECC) reinforced by ultra-highmolecular-weight polyethylene fiber (PE fiber) featuring both high mechanical strengths and high tensile ductility has been developed recently (Ranade et al., 2013; Curosu et al., 2017; Yu et al., 2018; Lei et al., 2019; Yu et al., 2020a). The compressive strength of HS-ECC ranges from 80 to over $150 \mathrm{MPa}$, and the tensile strength is in the range of $8-20 \mathrm{MPa}$. Besides, the tensile strain capacity of HS-ECC could reach $8.0 \%$ depending on the fiber types and fiber parameters (fiber volume, fiber length, and diameter) (Chen et al., 2018; Zhu et al., 2018; Li et al., 2019; Cai et al., 2021). Nevertheless, the crack width of HS-ECC is $120-200 \mu \mathrm{m}$, which is much wider than that of PVA-ECC because of the hydrophobicity of $\mathrm{PE}$ fiber and high matrix fracture toughness (Li et al., 2019), influencing adversely the self-healing potential of HS-ECC (Zhang and Zhang, 2017).

The rubber industry is developing at an alarming rate, while the improper disposal methods of scrap rubber, such as burning and landfill, have raised increasing environmental concerns. Using crumb rubber (CR) to replace partial fine aggregates in cementitious materials is an environmentally sustainable disposal method that is worthy of research. Despite the limited study on the use of CR in ECC, a consensus has been achieved that the addition of CR can enhance the tensile strain capacity and the cracking resistance of ECC by decreasing the toughness of the matrix (Huang et al., 2013; Zhang et al., 2015; Zhang et al., 2020b; Adesina and Das, 2021). Zhang et al. (2020b) found that cracks could be more easily triggered and the crack width could be reduced with $\mathrm{CR}$ addition to benefit the self-healing capacity of PVA-ECC. Accordingly, CR acting in artificial flaws within the matrix might also improve the crack robustness, reduce the crack width and density of HS-ECC, and modify its self-healing

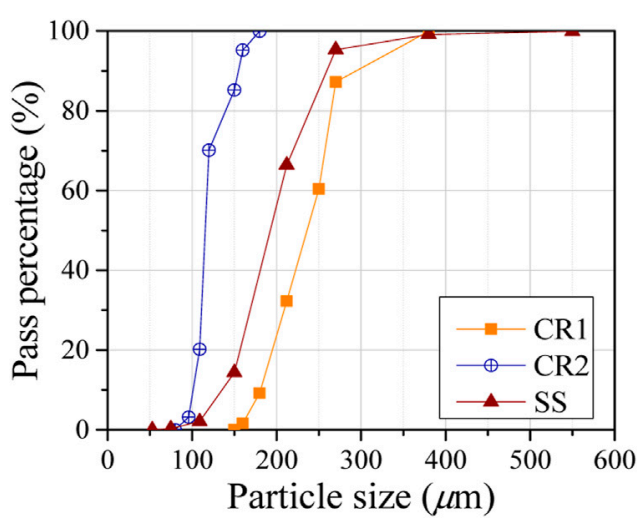

FIGURE 1 | Particle size distributions.

capacity, which has not been stressed before and remains to be fully clarified.

The objective of this research is to experimentally study the effects of CR particles on mechanical performance and selfhealing capacity of lightweight HS-ECC under cyclic wet-dry conditioning. CR as a fine aggregate in HS-ECC was used to totally substitute silica sand (SS) by equal volume with three different aggregate/binder ratios (i.e., $a / b=0.2,0.4$, and 0.6 ). In addition, CR with two particle sizes (i.e., CR1 and CR2) was adopted under $a / b=0.4$ to study the influence of particle size on the tensile behavior of HS-ECC. The HS-ECC specimen characterized with the smallest crack width (i.e., CR2-0.4) was selected to conduct the further self-healing tests. The CR2-0.4 specimen was preloaded to three certain tensile strains including $0.5 \%, 1.0 \%$, and $2.0 \%$ and experienced 7 wet-dry cycles before reloading. The degree of self-healing capacity of HS-ECC was evaluated by resonant frequency (RF) and tensile performance after recovery.

\section{EXPERIMENTAL PROGRAM}

\section{Mixture Preparation}

The binder materials used for HS-ECC consists of three parts, including ordinary Portland cement, silica fume (SF), and fly ash (FA). These binder materials along with a low water-to-binder ratio $(w / b)$ could generate sufficient C-S-H gel and homogenize the matrix to produce a high compressive strength under normal curing conditions. A polycarboxylate-based superplasticizer (SP) was used to gain proper mixture flowability. SS used as an aggregate had average and maximum particle sizes of 150 and $270 \mu \mathrm{m}$, respectively. CR with the density of $900 \mathrm{~kg} / \mathrm{m}^{3}$ and twoparticle size distributions (i.e., CR1 and CR2) was employed to totally replace SS in the HS-ECC by volume. The particle size distributions of SS and CR are shown in Figure 1. It is clear that the particle size of CR was comparable with that of SS, and CR2 was finer while CR1 was coarser than SS. CR having lower bond stress to the matrix can be considered as an artificial flaw in HS-ECC. 
TABLE 1 | Mix proportion of HS-ECC.

\begin{tabular}{|c|c|c|c|c|c|c|c|c|c|}
\hline Mix ID & $\begin{array}{l}\text { Cement } \\
\left(\mathrm{kg} / \mathrm{m}^{3}\right)\end{array}$ & $\mathrm{SF}\left(\mathbf{k g} / \mathrm{m}^{3}\right)$ & $\mathrm{FA}\left(\mathrm{kg} / \mathrm{m}^{3}\right)$ & $\mathrm{SS}\left(\mathbf{k g} / \mathrm{m}^{3}\right)$ & CR $\left(\mathbf{k g} / \mathrm{m}^{3}\right)$ & Water $\left(\mathbf{k g} / \mathrm{m}^{3}\right)$ & $\mathrm{SP}\left(\mathbf{k g} / \mathrm{m}^{3}\right)$ & Fiber $\left(\mathbf{k g} / \mathrm{m}^{3}\right)$ & $a / b$ \\
\hline SS-0.4 & 625.0 & 125.0 & 680.0 & 575.0 & 0 & 270.0 & 30.0 & 20 & 0.4 \\
\hline CR1-0.2 & 719.0 & 143.8 & 782.3 & - & 109.7 & 310.6 & 17.3 & 20 & 0.2 \\
\hline CR1-0.4 & 625.0 & 125.0 & 680.0 & - & 191.7 & 270.0 & 30.0 & 20 & 0.4 \\
\hline CR1-0.6 & 557.2 & 111.4 & 606.2 & - & 255.0 & 240.0 & 26.7 & 20 & 0.6 \\
\hline CR2-0.4 & 625.0 & 125.0 & 680.0 & - & 191.7 & 270.0 & 30.0 & 20 & 0.4 \\
\hline
\end{tabular}

Note. The solid content of SP is $40 \%$.

HS-ECC, high-strength engineered cementitious composite; SF, silica fume; FA, fly ash; SS, silica sand; CR, crumb rubber; SP, superplasticizer.

\section{A}

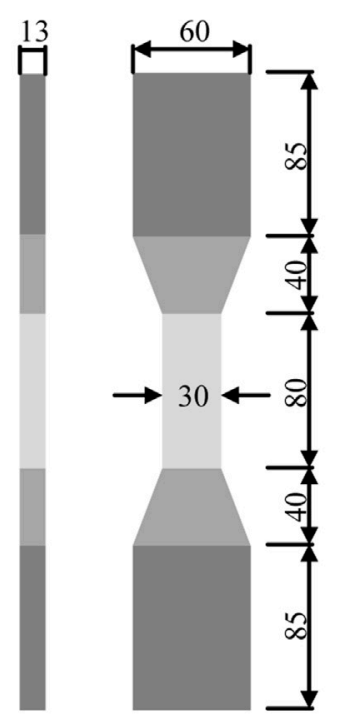

Dimensions of dogbone-shaped specimen
B

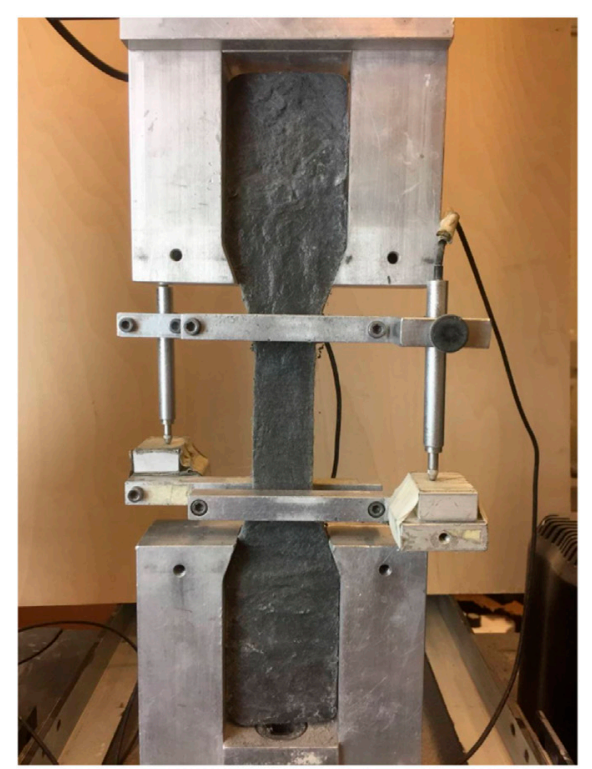

Uniaxial tension test set-up

FIGURE 2 | Specimen dimensions and test setup. (A) Dimensions of dog bone-shaped specimen. (B) Uniaxial tension test set-up.

High-strength PE fiber with a nominal tensile strength of $2,400 \mathrm{MPa}$ was used as the reinforcement in HS-ECC. The diameter and length of PE fiber were 24 and $18 \mathrm{~mm}$, respectively, resulting in an aspect ratio (i.e., $L_{\mathrm{f}} / d_{\mathrm{f}}$ ) of 750 , leading to a larger effective fiber/matrix interface area and a higher fiber-bridging capacity at the same fiber content (Naaman and Najm, 1991; Lin and Li, 1997). The PE fiber content was constant at $2 \%$ by volume for all the mixtures.

In order to study the influence of $\mathrm{CR}$ particles on the mechanical properties and self-healing capacity of HS-ECC, five HS-ECC mixtures were adopted in this study as listed in Table 1. The equivalent aggregate-to-binder $(a / b)$ ratios of HSECC with CR totally substituting SS by an equal volume of 0.2-0.6 were considered. In addition, the effect of CR particle sizes (i.e., CR1 and CR2) on the tensile properties of HS-ECC was investigated at an equivalent $a / b$ ratio of 0.40 .

All HS-ECC mixtures were prepared under the same mixing process. The solid materials, including cement, SF, FA, and CR/ SS, were firstly mixed for $30 \mathrm{~s}$. Then, water and SP were added slowly and mixed with the solid ingredients at low speed for
$5 \mathrm{~min}$, followed by a high speed mixing for $1 \mathrm{~min}$. Finally, fibers were gradually added in two batches and mixed at high speed until uniform distribution was achieved. The specimens were covered with plastic sheets after casting and were demolded after $24 \mathrm{~h}$. The specimens were cured at room temperature $\left(20^{\circ} \mathrm{C} \pm 1^{\circ} \mathrm{C}\right.$ and $40 \% \pm 5 \% \mathrm{RH}$ ) until 28 days.

\section{Mechanical Testing Procedure}

A direct tensile test was conducted $(50-\mathrm{kN}$ loading machine with a loading rate of $0.5 \mathrm{~mm} / \mathrm{min}$ ) to determine the full-range uniaxial tensile performance of HS-ECC, including the tensile strength, strain capacity, and crack patterns. The geometry of the dog bone-shaped specimen (Figure 2A) was designed to ensure that most of the cracks occur in the central gauge region (JSCE, 2008). A pair of linear variable displacement transducers (LVDTs) was attached with a gauge length of approximately $80 \mathrm{~mm}$ to measure the extension as shown in Figure 2B. During the test, multiple cracks penetrating through the thickness of the specimen accompanied with the strain-hardening behavior were observed. 
TABLE 2 | Testing scheme of HS-ECC.

Mix ID

Number of specimens

\begin{tabular}{ccc}
\hline Compression & Tension & Matrix three-point bending \\
3 & 5 & 6 \\
N/A & 5 & N/A
\end{tabular}

CR2-0.4-0.5, 1.0, 2.0\%

N/A

Note. HS-ECC, high-strength engineered cementitious composite.

The compressive strengths of HS-ECC at 28 days were determined by using $50.8 \mathrm{~mm}$ ( 2 in.) of cube specimens and were calculated by averaging three specimens. CR particles acting as artificial flaws could reduce the fracture toughness of HS-ECC matrix (without fiber), and the three-point bending tests were conducted to determine the fracture toughness of HS-ECC matrix. The dimensions of the specimen were $40 \mathrm{~mm} \times$ $40 \mathrm{~mm} \times 180 \mathrm{~mm}$ with a span/depth ratio of 4.0 and a prefabricated crack depth/specimen depth of 0.3 . The detailed testing scheme is shown in Table 2.

\section{Self-Healing Testing Procedure}

The HS-ECC mixture incorporating CR particles featuring sufficiently small crack widths under direct tension (i.e., CR20.4 ) was selected for the self-healing test. The CR2-0.4 specimens were preloaded to three tensile strain values of $0.5 \%, 1.0 \%$, and $2.0 \%$ to produce different damage levels as listed in Table 2. When the preset tensile strain values were reached, the specimens were unloaded and the crack widths were measured prior to wet-dry cycle conditioning. Afterward, the pre-cracked CR2-0.4 specimens were cured under wet-dry cycles, which is an accelerated testing method to simulate actual outdoor environments. One wet-dry cycle of the specimens includes submersion in water at $20^{\circ} \mathrm{C} \pm 1{ }^{\circ} \mathrm{C}$ for $48 \mathrm{~h}$ and then drying in laboratory air at $20^{\circ} \mathrm{C} \pm 1^{\circ} \mathrm{C}$ and $40 \% \pm 5 \% \mathrm{RH}$ for $48 \mathrm{~h}$. Water was replaced after each cycle. After undergoing 7 wet-dry cycles (28 days in total), the cured specimens were retested until failure. The tensile mechanical properties and crack patterns were employed to assess the self-healing capacity of HS-ECC with CR substitution.

In addition to the uniaxial tension test, longitudinal RF measurements (ASTM, 2019) were carried out on dog boneshaped specimens to verify the presence of damage and quantify the extension of autogenous self-healing in HS-ECC according to the changes in RF. The RF values of the intact and pre-damaged CR2-0.4 specimens after each wet-dry curing were recorded. The change of RF can be regarded as an indicator to assess the damage degree of pre-damaged HS-ECC specimens and the recovery extension of self-healed HS-ECC specimens.

\section{RESULTS AND DISCUSSION Compressive Strength, Density, and Fracture Toughness}

The compressive strength of HS-ECC at 28 days is demonstrated in Figure 3. As expected, the total substitution of SS with CR particles has demonstrated a significantly adverse effect on the

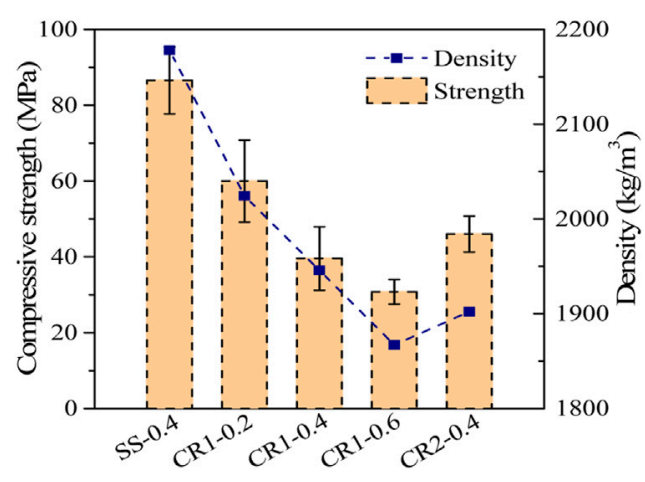

FIGURE 3 | Compressive strength and density of HS-ECC. HS-ECC, high-strength engineered cementitious composite.

compressive strength. Compared with the reference mixture of HS-ECC using SS as aggregate (i.e., SS-0.4) whose compressive strength is $86.6 \mathrm{MPa}$, the compressive strength of HS-ECC when SS is entirely replaced by CR by equal volume (i.e., CR1-0.4) reduces to $39.6 \mathrm{MPa}$ with a $54.3 \%$ reduction. Besides, a higher amount of $\mathrm{CR}$ leads to a more obvious reduction in the compressive strength as shown in Figure 3. For instance, the compressive strength of CR-modified HS-ECC decreases from 60.0 to $30.8 \mathrm{MPa}$ as the equivalent $a / b$ ratio increases from 0.2 to 0.6. The loss of the compressive strength of HS-ECC with CR substitution can be attributed to the lower stiffness of CR particle compared with SS, the increment of closed pores within the matrix caused by CR addition (Oikonomou and Mavridou, 2009), and the weak interfacial bond between the CR and around the cementitious matrix. Moreover, comparing the compressive strength of CR1-0.4 and CR2-0.4 in Figure 3, it is evident that the negative impact on the compressive strength due to $\mathrm{CR}$ substitution can be diminished to a certain degree by using CR with a smaller particle size (i.e., CR2-0.4). It is also clear that all the CR-modified HS-ECC mixtures could be utilized for structural applications, as the compressive strengths are higher than $30 \mathrm{MPa}$.

The density of HS-ECC mixtures is also drawn in Figure 3. The incorporation of CR as a complete replacement of SS reduces the density of HS-ECC, and the density is positively correlated to the compressive strength of HS-ECC in general. It is noted from Figure 3 that the density value decreases from $2,024 \mathrm{~kg} / \mathrm{m}^{3}$ of CR1-0.2 to $1,867 \mathrm{~kg} / \mathrm{m}^{3}$ of CR1-0.6 with a $7.7 \%$ reduction as the proportion of CR increases. Although CR2-0.4 with a smaller CR particle size exhibits a higher compressive strength, it has a 


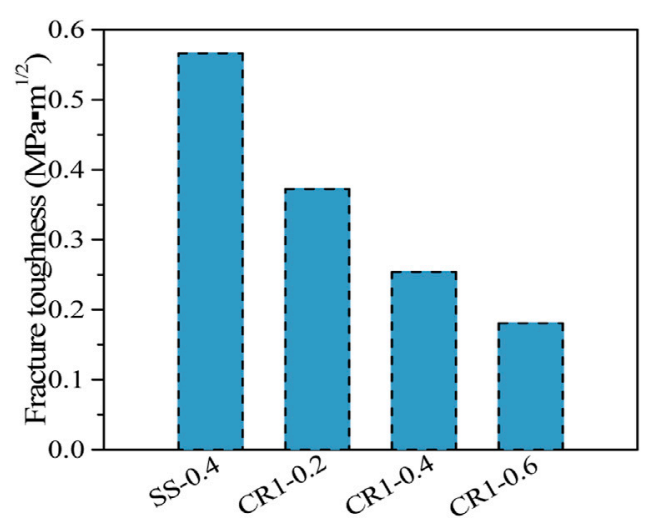

FIGURE 4 | Fracture toughness of HS-ECC. HS-ECC, high-strength engineered cementitious composite.

slightly lower density than CR1-0.4 with a larger CR particle size. In accordance with American Concrete Institute (ACI) committee report (American Concrete Institute, 2003), the density of lightweight cementitious composites for structural applications should be $1,120-1,920 \mathrm{~kg} / \mathrm{m}^{3}$ with a compressive strength at 28 days of more than $40 \mathrm{MPa}$. Thus, HS-ECC mixtures produced with $100 \% \mathrm{CR} 2$ at an $a / b$ ratio of 0.4 (i.e., CR2-0.4) can be classified as lightweight cementitious composites because their density is $1,902 \mathrm{~kg} / \mathrm{m}^{3}$ and compressive strength is $50.0 \mathrm{MPa}$.

According to the results of the three-point bending test, the fracture toughness of HS-ECC matrix with different CR proportions is obtained and shown in Figure 4. It can be found that the fracture toughness of HS-ECC matrix decreases steadily with the increase of CR proportion. Similar to the compressive strength, the fracture toughness of HS-ECC decreases sharply from $0.57 \mathrm{MPa} \cdot \mathrm{m}^{1 / 2}$ of $\mathrm{SS}-0.4$ to $0.25 \mathrm{MPa} \cdot \mathrm{m}^{1 / 2}$ of CR1-0.4 when CR was used to completely replace SS by equal volume. Besides, the fracture toughness decreases gradually from 0.37 to $0.18 \mathrm{MPa} \cdot \mathrm{m}^{1 / 2}$ when the equivalent $a / b$ ratio increases from 0.2 to 0.6 . Designed based on the micromechanical model, two criteria (strength and energy criterion) should be satisfied to achieve the strain-hardening performance and multi-cracking states of ECC (Li and Leung, 1992). In order to achieve high tensile ductility and saturated multiple microcracks, the size and distribution of internal flaws should be tailored (Zhang et al., 2021). Reducing the critical flaw size by introducing artificial flaws such as CR whose interfacial bond stress with a cementitious matrix is relatively low can be regarded as an effective way to reduce matrix fracture toughness and thus activate more microcracks (Li and Wang, 2006; Zhang et al., 2020a), which could benefit the self-healing capacity of HS-ECC.

\section{Tensile Mechanical Properties}

Figure 5 presents the tensile stress-strain curves of HS-ECC specimens with different CR contents. All the HS-ECC specimens exhibit robust strain-hardening performance under uniaxial tension. The tensile strain capacities of all HS-ECC specimens at peak stress are higher than $6 \%$, as well as the tensile elongations at breakage are higher than $12 \%$. As shown in Figures $5 \mathbf{A}-\mathbf{E}$, it is clear that the substitution of SS by CR has a dramatic influence on the full-range tensile stress-strain curve of HS-ECC. Comparing Figures $\mathbf{5 A}, \mathbf{B}$, it is clear that the incorporation of $\mathrm{CR}$ with a larger particle size (i.e., CR1) than SS by equal volume decreases the peak tensile strength of HS-ECC distinctly while increasing the tensile strain capacity slightly. Besides, the replacement of SS by CR with a smaller particle size (i.e., CR2) than SS by equal volume as shown in Figures 5A,E affects marginally both the peak tensile strength and tensile strain capacity of HS-ECC. However, the CR2-0.4 specimen exhibits an obvious secondary hardening stage with a higher modulus as observed in Figure 5E. It might be because CR2 with a finer particle size introduces more artificial flaws into the matrix, and the majority of the cracks are activated in the first hardening stage, exhibiting obvious fluctuation. Then, limited cracks are newly generated in the secondary hardening stage, and slip-hardening behavior is observed to be accompanied by crack opening. Moreover, it also suggests that the increased proportion of CR (i.e., $a / b$ increases from 0.2 to 0.6 ) benefits the performance of HS-ECC in terms of tensile ductility, whereas it has an adverse effect on the tensile strength as illustrated in Figures 5B-D.

The key tensile parameters of HS-ECC, including the peak and initial cracking stress $\left(\sigma_{\mathrm{tu}}\right.$ and $\left.\sigma_{\mathrm{tc}}\right)$, the tensile strain capacity $\left(\varepsilon_{\mathrm{tu}}\right)$, the strain energy density $\left(g_{\mathrm{se}}\right)$, and the fracture energy $\left(G_{\mathrm{f}}\right)$, are summarized in Table 3. The definition and calculation method of $g_{\text {se }}$ and $G_{\mathrm{f}}$ can be referred to in previous research (Yu et al., 2020b). Put simply, the strain energy density is the area enclosed by the strain-hardening branch of the tensile stress-strain curve, representing the energy dissipation capacity during the strainhardening process, whereas the fracture energy is approximately equal to the area under the descending stage of the load-displacement curve, reflecting the energy dissipation capacity after crack localization during the strain-softening process.

The critical tensile parameters of HS-ECC are presented in Figure 6. The peak tensile strength of HS-ECC decreases from 11.73 MPa of SS-0.4 to $6.71 \mathrm{MPa}$ of CR1-0.4 when CR1 is used to completely replace SS by equal volume (Figure 6A). CR particles with a larger particle size inside HS-ECC are enclosed by the matrix and loosen the matrix structure (Wang et al., 2020), and the peak tensile strength can be reasonably reduced. Besides, the larger particle size of CR1 compared with SS may disturb the fiber dispersion, resulting in the reduction of interfacial bond stress between PE fiber and matrix, leading to a further decrease in the peak tensile stress. Nevertheless, the peak tensile strength of HS-ECC with CR2 substitution (i.e., CR2-0.4) generates a comparable peak tensile strength with SS-0.4. This might be because CR2 has a finer and more irregular particle size than SS, alleviating the negative influences introduced by CR substitution. Moreover, it is noted from Figure 6A that with the increase of CR1 proportion, the peak tensile strength of HS-ECC reduces from $8.75 \mathrm{MPa}$ of CR1-0.2 to $4.60 \mathrm{MPa}$ of CR1-0.6 with a $47.4 \%$ reduction, which is mainly caused by the weakened matrix structure. Similarly, the reduced initial tensile stress of HE-ECC with CR particle 


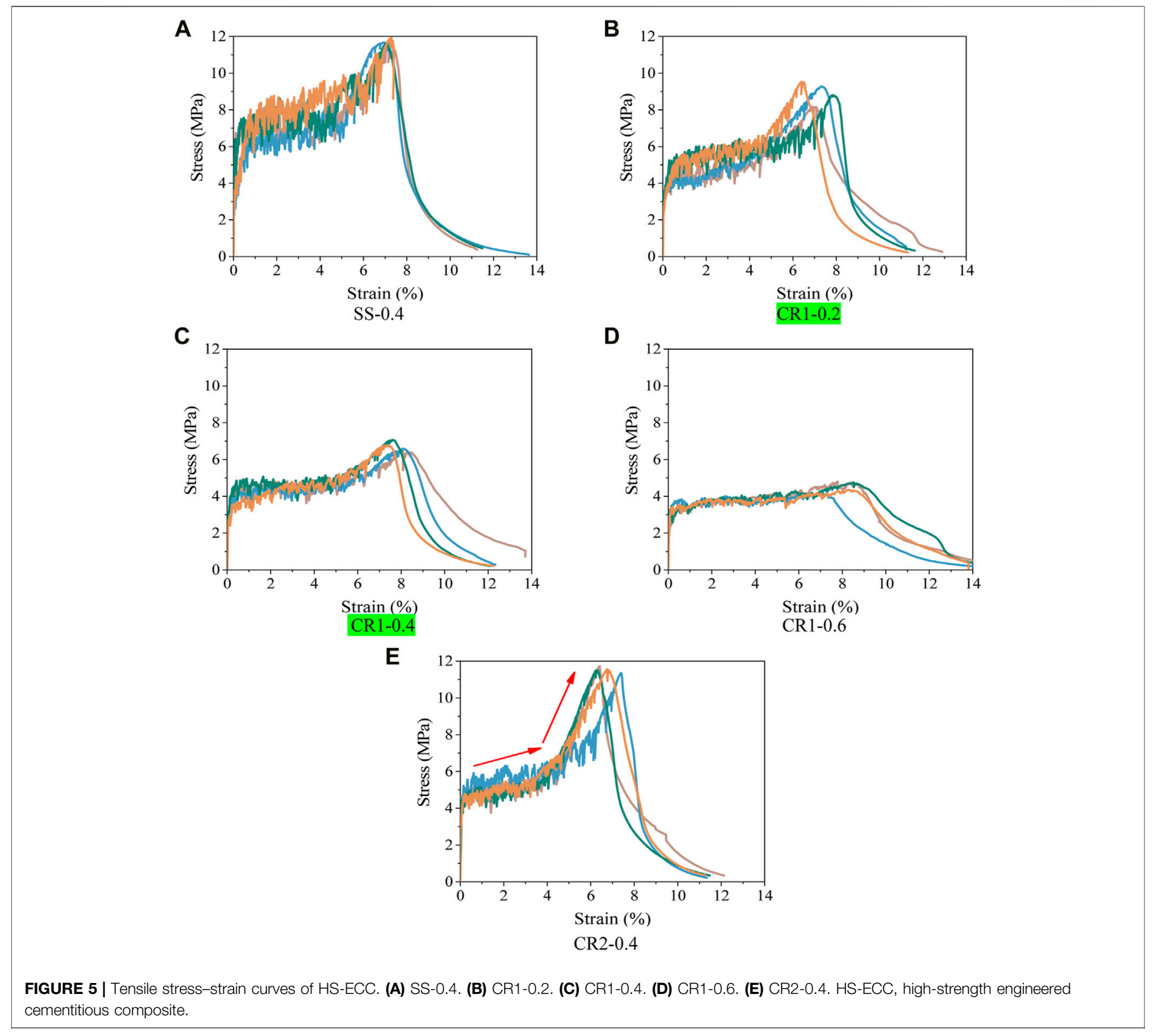

\begin{tabular}{|c|c|c|c|c|c|c|}
\hline Mix ID & $\sigma_{\mathrm{tc}}(\mathrm{MPa})$ & $\sigma_{\mathrm{tu}}(\mathrm{MPa})$ & $\varepsilon_{\mathrm{tu}}(\%)$ & $g_{\mathrm{se}}\left(\mathrm{kJ} / \mathrm{m}^{3}\right)$ & $G_{\mathrm{f}}\left(\mathrm{kJ} / \mathrm{m}^{2}\right)$ & $G_{\mathrm{f}} / \sigma_{\mathrm{tu}}$ \\
\hline SS-0.4 & 4.36 & 11.73 & 7.14 & 565.8 & 14.84 & 1.27 \\
\hline CR1-0.4 & 3.09 & 6.71 & 7.76 & 369.5 & 11.84 & 1.76 \\
\hline CR1-0.6 & 2.89 & 4.60 & 7.63 & 294.3 & 12.04 & 2.62 \\
\hline CR2-0.4 & 4.13 & 11.39 & 6.67 & 421.7 & 15.06 & 1.32 \\
\hline
\end{tabular}

Note. HS-ECC, high-strength engineered cementitious composite.

substitution could be contributed to the decrease in matrix fracture toughness.

As shown in Figure 6B, the influence of CR substitution and CR proportion on the tensile strain capacity of HS-ECC is slight. The strain capacity of SS-0.4 is $7.14 \%$, and this value increases mildly to $7.76 \%$ of CR1-0.4. It is noted from Figure 6C that the strain energy density shares a similar trend with that of the tensile strength (Figure 6A). The strain energy density of SS-0.4 (i.e., $565.8 \mathrm{~kJ} / \mathrm{m}^{3}$ ) is approximately 1.5 times that of CR1-0.4 (i.e., $369.5 \mathrm{~kJ} / \mathrm{m}^{3}$ ) due to the decrease of tensile stress. Moreover, 


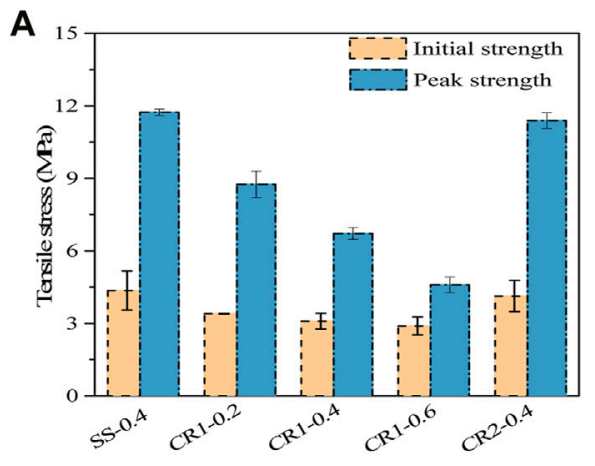

Tensile strength

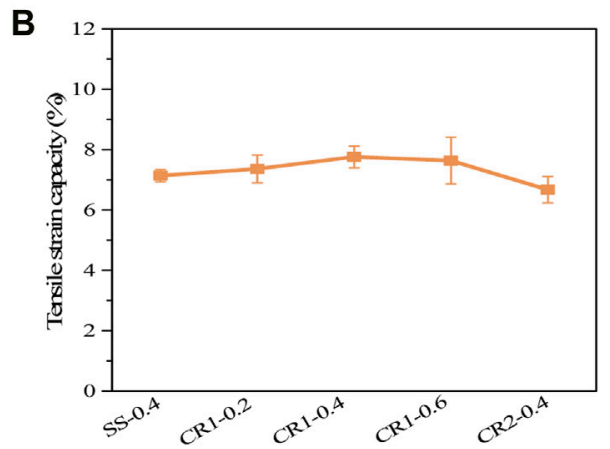

Tensile strain capacity

C

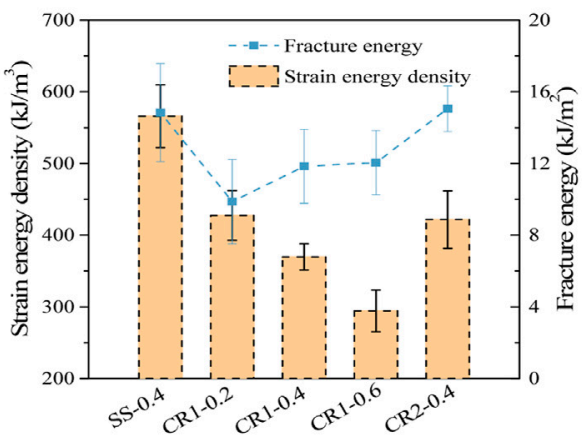

Strain energy density and fracture energy

FIGURE 6 | Tensile mechanical parameters of HS-ECC. (A) Tensile strength. (B) Tensile strain capacity. (C) Strain energy density and fracture energy. HS-ECC, high-strength engineered cementitious composite.

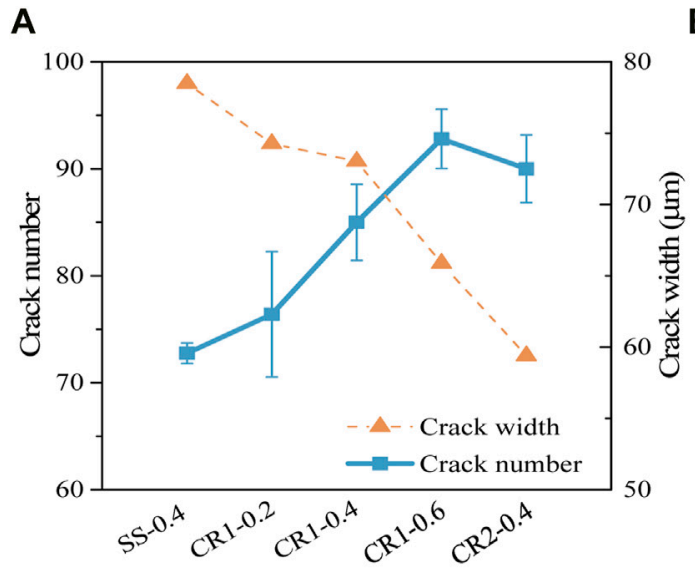

Crack number and crack width
B
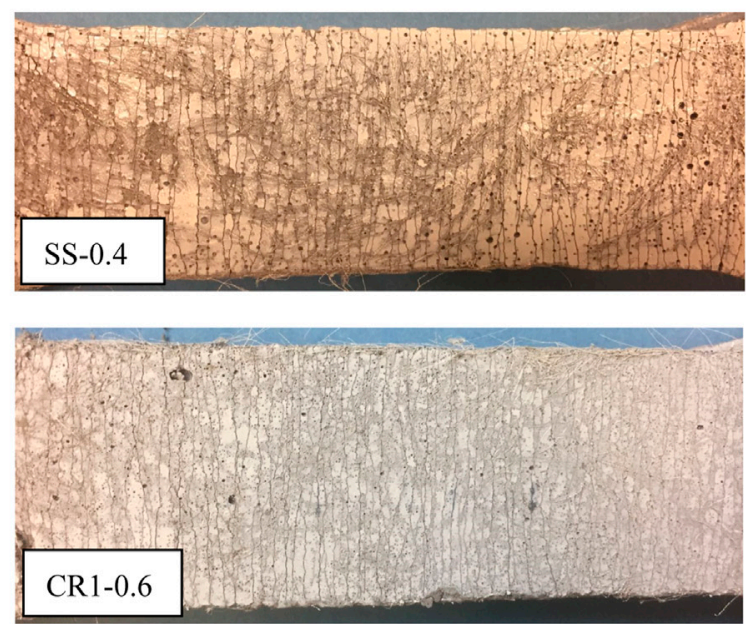

Crack distribution of SS-0.4 and CR1-0.6

FIGURE 7 | Crack parameters of HS-ECC. (A) Crack number and crack width. (B) Crack distribution of SS-0.4 and CR1-0.6. HS-ECC, high-strength engineered cementitious composite.

the fracture energy of HS-ECC decreases as SS is entirely replaced by CR1 by equal volume, which is caused by the much lower peak tensile strength of CR1-0.4 (Figure 6C). Normalizing the fracture energy by the peak tensile strength (i.e., $G_{\mathrm{f}} / \sigma_{\mathrm{tu}}$ ) as listed in Table 3, it is noted that the larger $G_{\mathrm{f}} / \sigma_{\mathrm{tu}}$ ratio combined with the lower fracture energy as well as the lower peak tensile strength 
TABLE 4 | Crack parameters of preloaded CR2-0.4

\begin{tabular}{lcc}
\hline Pre-tensile strain (\%) & Crack number & Crack width $(\boldsymbol{\mu m})$ \\
\hline 0.5 & 9 & 43 \\
1.0 & 17 & 48 \\
2.0 & 27 & 59
\end{tabular}

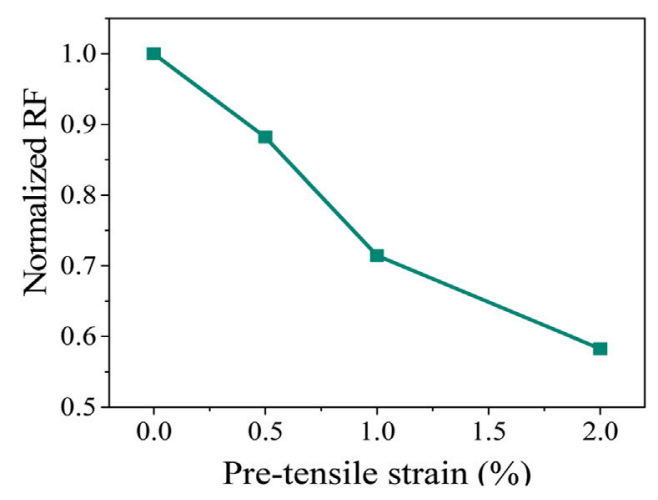

FIGURE 8 | Normalized RF of pre-damaged CR2-0.4. RF, resonant frequency.

values of CR1-0.4 compared with that of SS-0.4 indicates a gentler descending branch and a better energy consumption capacity after crack localization of HS-ECC with CR substitution. Additionally, it is also found from Table 3 that the $G_{\mathrm{f}} / \sigma_{\mathrm{tu}}$ ratio increases from 1.13 to 2.62 gradually as CR1 proportion improves from 0.2 to 0.6 , demonstrating the positive influence of CR addition on energy absorption capacity and ductility after crack localization.

\section{Crack Patterns}

Figure 7A shows the crack number and crack width of CRmodified HS-ECC. It should be stressed that the crack number increases obviously from 73 to 85 when CR1 is used to totally replace SS. Simultaneously, with the increase of CR1 proportion from 0.2 to 0.6 , the activated crack number of HS-ECC improves gradually from 76 to 93 with a $22.4 \%$ increment. As observed in Figure $7 \mathbf{B}$, the crack distributions of CR1-0.6 are more saturated than those of SS-0.4. Nevertheless, an opposite trend with CR1 proportion is observed for the crack width in general. The average crack width of HS-ECC using SS as a fine aggregate is approximately $80 \mu \mathrm{m}$. This value decreases to $73 \mu \mathrm{m}$ when CR1 is used to replace SS by equal volume, and the refining effect on crack width can be further enhanced to reduce the crack width to $59 \mu \mathrm{m}$ when CR2 with a smaller particle size is adopted. Apparently, the replacement of SS by CR can activate more microcracks as well as reduce the crack width by introducing artificial flaws and decreasing the matrix fracture toughness as shown in Figure 4, enhancing the self-healing potential of HS-ECC.

\section{Self-Healing Properties of High-Strength Engineered Cementitious Composite Properties of Pre-Damaged CR2-0.4}

The high-strength lightweight CR2-0.4 specimens exhibiting the smallest average crack width of $59 \mu \mathrm{m}$ corresponding to the peak stress are selected to further explore the self-healing properties of HS-ECC. Table 4 summarizes the crack pattern of the CR2-0.4 specimens preloaded to three strain levels, i.e., $0.5 \%, 1.0 \%$, and $2.0 \%$. The crack number increases with the increase of preloaded strain level from $9 \%$ at $0.5 \%$ to $27 \%$ at $2.0 \%$, and a similar trend is observable in the average crack width at the loading stage that grows from 43 to $59 \mu \mathrm{m}$.

The normalized RF for the pre-cracked CR2-0.4 specimens preloaded to strain levels of $0.5 \%, 1.0 \%$, and $2.0 \%$ is plotted in Figure 8. With the increase of pre-strain level, the normalized RF value decreases and expresses an almost linear relationship. The normalized RF gradually decreases from 0.88 at a pre-tensile strain of $0.5 \%$ to 0.58 at a pre-tensile strain of $2.0 \%$. The increased

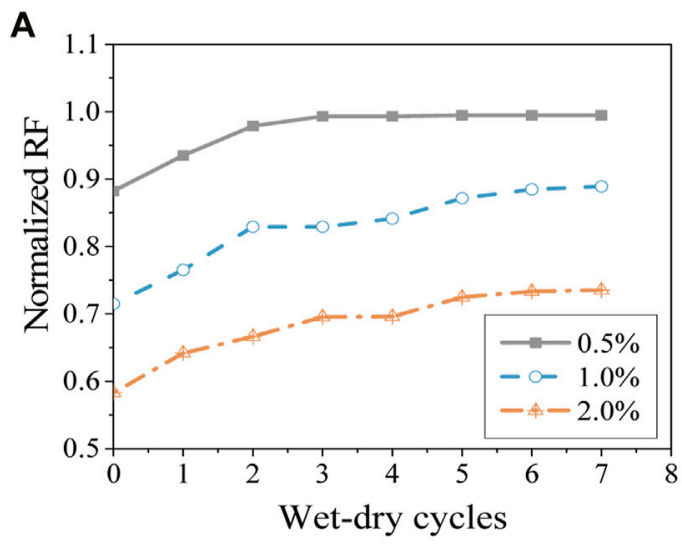

Normalized RF after each wet-dry cycle

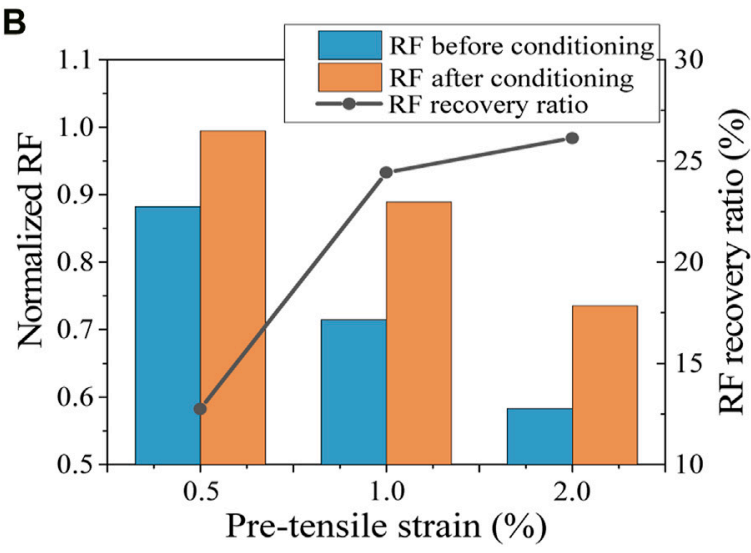

RF recovery ratio

FIGURE 9 | RF of CR2-0.4 after wet-dry cycles. (A) Normalized RF after each wet-dry cycle. (B) RF recovery ratio. RF, resonant frequency. 


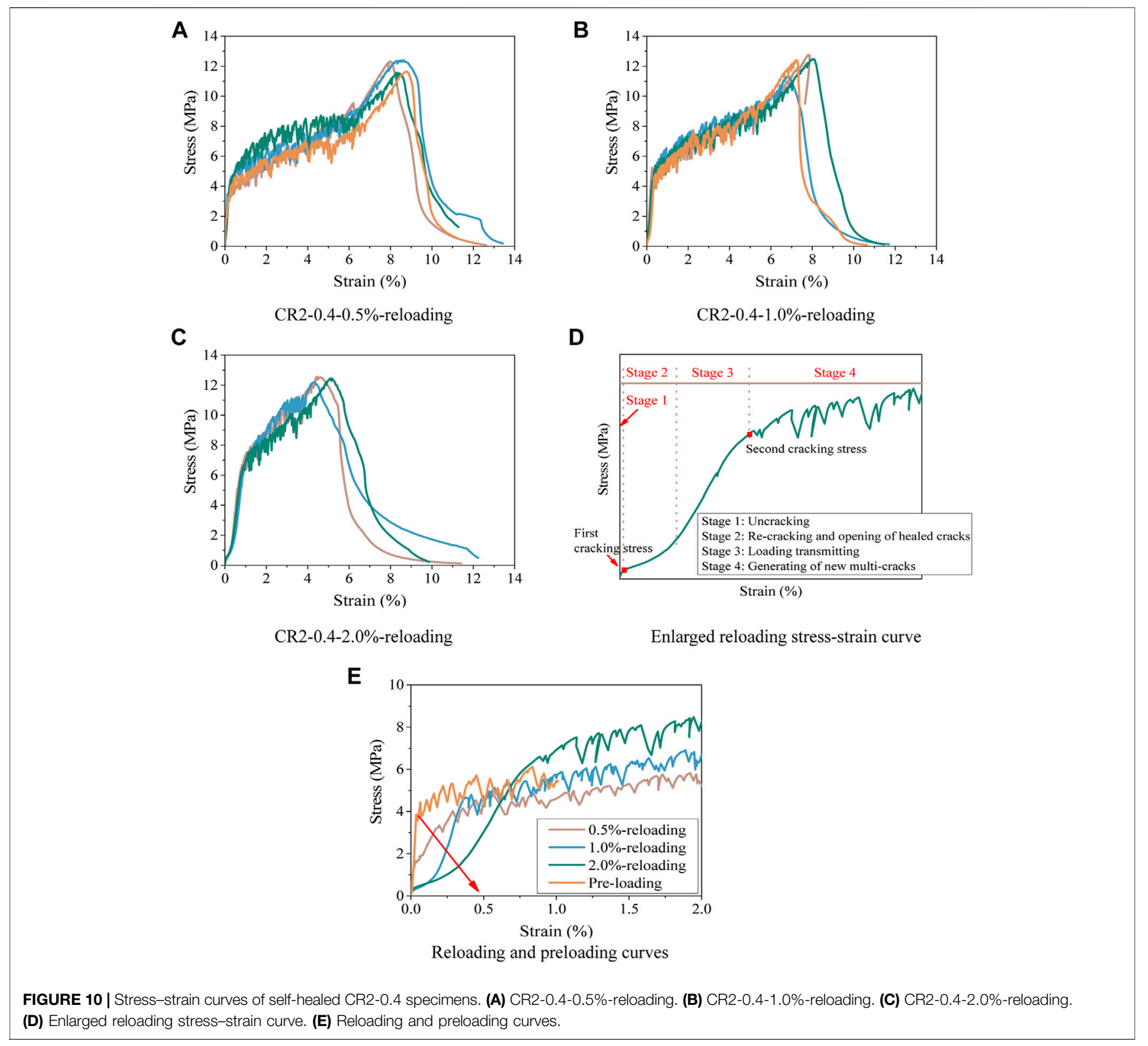

crack number as well as the enlarged crack width could be the reason for the decrease of RF.

\section{Resonant Frequency Recovery}

The normalized RF recovery of the pre-cracked CR2-0.4 specimens before and after every wet-dry cycle is recorded and plotted in Figure 9A. At least three specimens are prepared to monitor the RF recovery. The RF of the CR2-0.4 specimens is normalized by the value of uncracked (virgin) specimens. Therefore, a high RF ratio represents a high recovery degree, which can be attributed to further hydration during the wet-dry conditioning regimes. Apparently, the CR20.4 specimens preloaded to a higher damage level show a lower RF both before and after wet-dry cycles. It is clear from Figure 9A that $\mathrm{RF}$ recovery mainly happens in the first $2-5$ wet-dry cycles.
After 7 wet-dry cycles, the normalized RF of the CR2-0.4 specimens regains beyond $99 \%, 89 \%$, and $73 \%$ for $0.5 \%, 1.0 \%$, and $2.0 \%$ pre-strained specimens, respectively. For the CR2-0.4 specimens preloaded to a lower strain level (i.e., $0.5 \%$ ), the tighter distributed cracks with tinier crack widths (i.e., $43 \mu \mathrm{m}$ ) are more easily filled with healing products, and the RF can recover up to almost $100 \%$ of the uncracked specimen after only 2-3 cyclic wet-dry exposures. Nonetheless, for the CR2-0.4 specimens with more severe damage (i.e., a pre-tensile strain of $2.0 \%$ with a crack width of $59 \mu \mathrm{m}$ ), the hydration products generated during the wet-dry cycles accumulated at the microcrack surface might hinder the further hydration inside the microcrack, leading to a lower RF after healing. Moreover, the RF value for the CR2-0.4 specimens pre-damaged mildly tends to be faster compared with those pre-damaged seriously. 


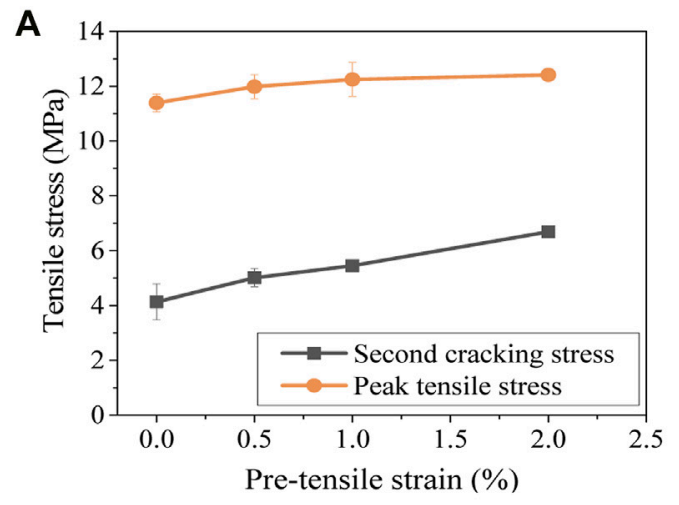

Tensile stress

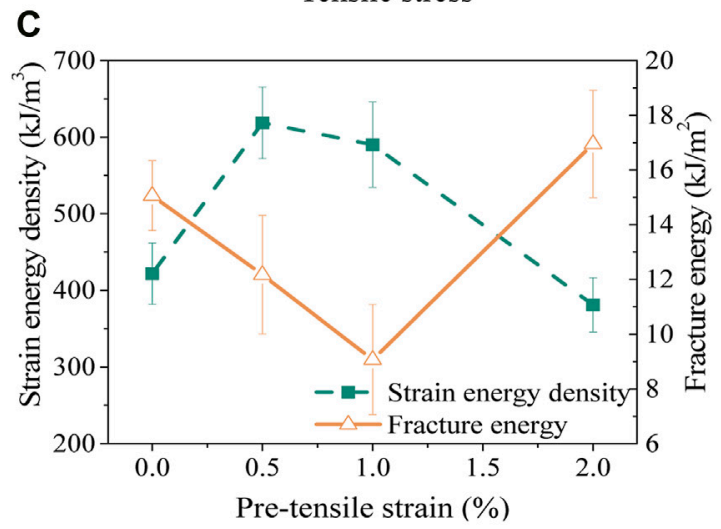

Strain energy density and fracture energy
B

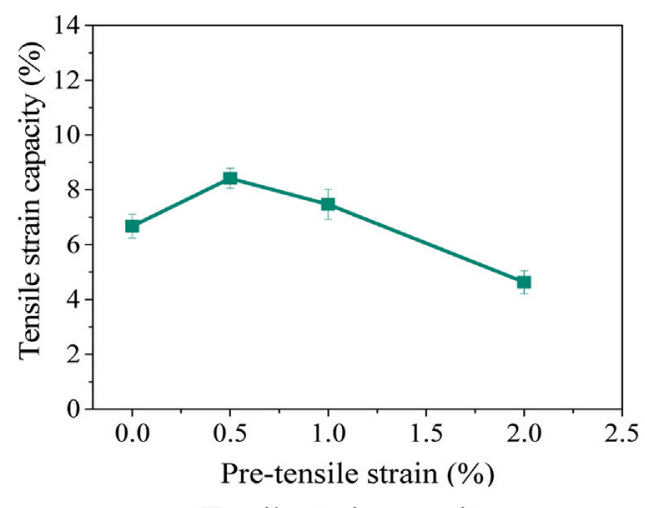

D

Tensile strain capacity

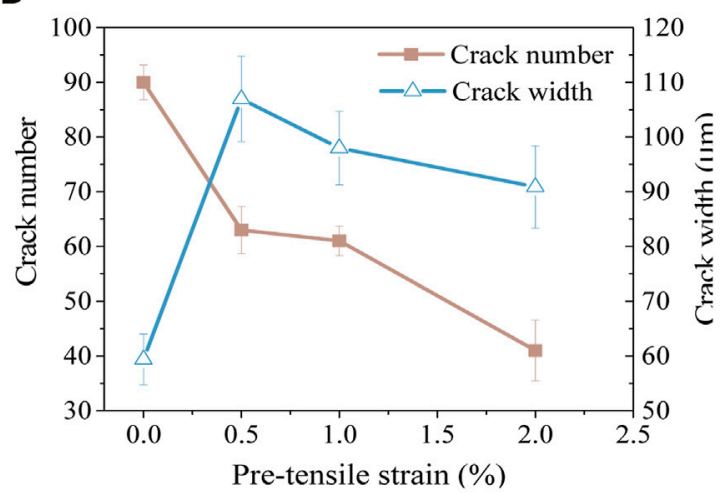

Crack number and crack width

FIGURE 11 | Tensile parameters of reloading CR2-0.4 specimens. (A) Tensile stress. (B) Tensile strain capacity. (C) Strain energy density and fracture energy. (D) Crack number and crack width.

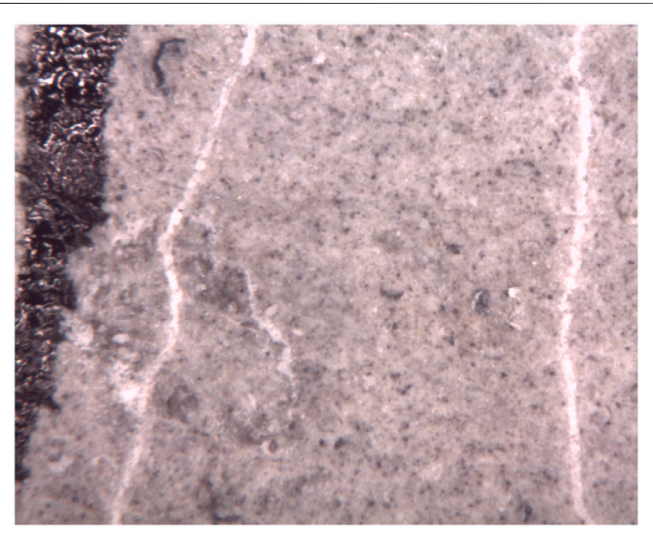

FIGURE 12 | Self-healing CR2-0.4-0.5\% specimen surface after 7 wet-dry conditioning.

The extent of the RF recovery ratio of the CR2-0.4 specimens after 7 wet-dry cycles for three pre-strain levels is shown in Figure 9B. The ratio of RF recovery increases with the increase of preloading strain levels, meaning that the opportunity of crack healing can be enhanced by experiencing more damage in the form of crack numbers. Although the RF recovery ratio of the
CR2-0.4 specimen pre-stretched to $2.0 \%$ tensile strain is relatively high (i.e., 26.1\%), its self-healing capacity after curing conditioning is inadequate with an $\mathrm{RF}$ value of $73.5 \%$ of the intact one due to the wider crack width.

\section{Tensile Mechanical Performance Recovery}

The reloading tensile stress-strain curves of the self-healed CR20.4 specimens preloaded to three tensile strains, including $0.5 \%$, $1.0 \%$, and $2.0 \%$, are plotted in Figures 10A-C. All the predamaged and self-healed CR2-0.4 specimens exhibit significant strain-hardening performance as virgin specimens. It is worth noting that the residual strain induced during the preloading stage is neglected in the reloading stress-strain curves, expressing a conservative record of the tensile strain capacities of the selfhealed specimens. As can be seen from Figures 10A-C, the reloaded CR2-0.4 specimens express a similar tensile strength whereas decreased tensile strain capacity with the increasing predamage level. The maintained tensile strength can be because water can penetrate through the cracks and the continued hydration can enhance the fiber/matrix interfacial bond during the self-healing process. Thus, the more pre-formed the cracks are, the higher the tensile strength recovery. Besides, as can be seen from the local enlarged stress-strain curve in Figure 10D, the reloading tensile process can be divided into four stages. Stage 
1 with higher stiffness indicates that the self-healed matrix filled by the re-hydration products is uncracked; Stage 2 with much lower stiffness relates to the re-cracking and opening of the selfhealed cracks, which offers less resistance to load; Stage 3 exhibits higher stiffness compared with Stage 2, more and more fibers reengaged to bridge the cracks and transmit tensile load; and further loading causes Stage 4 features with the strainhardening process. Further, the enlarged preloading stress-strain curves of the virgin CR2-0.4 specimen and the reloading curves of the self-healed CR2-0.4 specimens after wet-dry cycles are compared in Figure 10E. It is stressed that the stiffness of Stage 3 of reloading specimens, which is defined as the recovery stiffness of the self-healed specimens in this study, reduces with the increasing pre-tensile strain due to the aggravation of initial damage. As expected, the stiffness of the virgin CR2-0.4 specimen is much higher than the recovery stiffness of self-healed specimens during reloading (Figure 10E).

Figure 11 compares the tensile parameters of the virgin CR2-0.4 specimens and those of reloaded specimens. It is noted from Figure 11A that not only the peak tensile stress but also the second cracking stress (Figure 10D) increases with higher pretensile strain. The peak tensile stress of virgin specimens is $11.39 \mathrm{MPa}$, and this value increased to $12.41 \mathrm{MPa}$ of the specimen with a $2 \%$ pre-strain. This could be attributed to the further hydration of unreacted cementitious materials during the wet-dry curing process, leading to an improvement in the interfacial fiber/matrix bond stress, which causes a higher ultimate strength of the self-healed specimens. Accordingly, a full tensile strength recovery can be achieved after self-healing of the pre-damaged CR2-0.4 specimens. In addition, the second cracking stress represents a more obvious increment from $4.13 \mathrm{MPa}$ of the virgin specimen to $6.69 \mathrm{MPa}$ with an increase of $38.3 \%$ as the pre-damage level increases to $2.0 \%$, demonstrating the effective tensile loading transition capacity of the pre-cracked location. Moreover, the first cracking stress of all the self-healed CR2-0.4 specimens is quite small at approximately $0.3-0.5 \mathrm{MPa}$ as shown in Figures 11A-C, indicating that self-healing products are relatively weak as compared with the original matrix.

The tensile strain capacity of the reloaded CR2-0.4 specimens reduces from $8.42 \%$ at $0.5 \%$ pre-strain to $4.63 \%$ at $2.0 \%$ pre-strain (Figure 11B). Similarly, the crack number also decreases obviously from 63 to 41 with a $34.9 \%$ reduction within the same pre-damage level range as shown in Figure 11D. Both phenomena can be attributed to the improvement in matrix toughness caused by the further hydration of the matrix. However, it should be noted from Figure 11B that the tensile strain capacities of the reloaded CR2-0.4 specimens with relatively small tensile strain levels of $0.5 \%$ and $1.0 \%$ are higher than those of the virgin specimen, which could contribute to the wider crack width.

Comparing Figures 11B,C, it can be seen that the strain energy density shares a similar trend with that of strain capacity, which increases obviously from $421.7 \mathrm{~kJ} / \mathrm{m}^{3}$ of the virgin specimen to $618.7 \mathrm{~kJ} / \mathrm{m}^{3}$ of CR2-0.4-0.5\% (i.e., $11 \%$ increase) and then gradually decreases to $381.1 \mathrm{~kJ} / \mathrm{m}^{3}$ as the pre-damage level increases to $2.0 \%$. On the contrary, the fracture energy decreases from $15.06 \mathrm{~kJ} / \mathrm{m}^{2}$ of the virgin CR2-0.4 specimens to

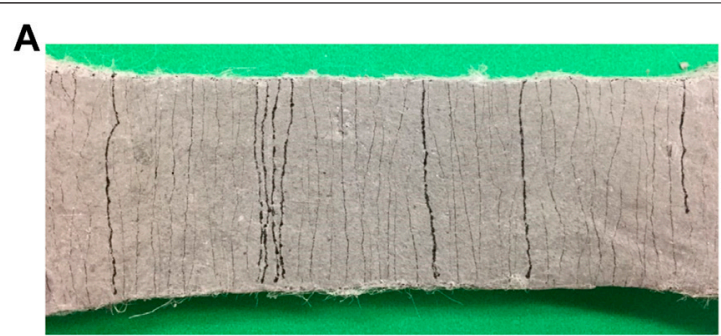

B

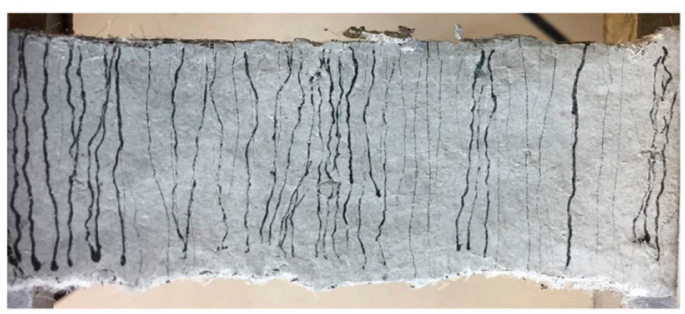

FIGURE 13 | Comparison of crack pattern for CR2-0.4 specimens before and after curing and reloading: (A) $0.5 \%$ pre-tensile strain and (B) $2.0 \%$ pre-tensile strain.

$12.17 \mathrm{~kJ} / \mathrm{m}^{2}$ of CR2-0.4-0.5\% and further reduces to $9.07 \mathrm{~kJ} / \mathrm{m}^{2}$ of CR2-0.4-1.0\% due to the sharper descending branch. The above results confirm the self-healing capacity of HS-ECC material in the form of rehabilitation of tensile properties to some degree.

After self-healing, the white residue products along the crack lines after wet-dry conditioning can be observed in Figure 12. As mentioned before, the average crack width for the CR2-0.4 specimens preloaded to $0.5 \%$ tensile strain is about $43 \mu \mathrm{m}$ as listed in Table 4. According to previous research, the majority of self-healed products are a combination of calcium carbonate crystals and calcium silicate hydrate gels (Kan and Shi, 2012).

The crack patterns for the CR2-0.4 specimens preloaded to $0.5 \%$ and $2.0 \%$ strain capacity and after curing and reloading are compared in Figure 13. The black lines were marked to represent cracks formed during the preloading stage. New cracks seem to follow and propagate along the pre-formed and self-healed cracks, indicating that self-healing products have a weaker structure than the original hydrated cementitious matrix. Thus, cracks are prone to generate and reopen on the previous crack location, resulting in an extremely small first cracking stress and low stiffness of Stage 2 in Figure 10D. At the same time, new cracks and crack paths are also observed to develop adjacent to previously self-healed cracks on new locations, resulting in Stage 3 and Stage 4 in Figure 10D and resuming the multiple cracking behaviors of self-healed HS-ECC specimens. Certainly, the selfhealed cracks are capable to transmit the tensile load effectively to cause new cracking, demonstrating the recovery of mechanical properties through the self-healing process.

\section{CONCLUSION}

A sustainable lightweight HS-ECC is developed by substituting SS completely by CR in this study, and the self-healing behavior of a 
series of CR-modified HS-ECC specimens preloaded to three certain tensile strains including $0.5 \%, 1.0 \%$, and $2.0 \%$ is investigated. $\mathrm{CR}$ as a fine aggregate in HS-ECC replaces SS entirely with three equivalent aggregate/binder ratios (i.e., $a / b=$ $0.2,0.4$, and 0.6) and two-particle sizes (i.e., CR1 and CR2) at $a / b=$ 0.4. According to the uniaxial tensile test results, the HS-ECC specimen that exhibits the smallest crack width (i.e., CR2-0.4) is selected to further conduct the self-healing tests. The rate and extent of self-healing behavior of the CR2-0.4 specimens are evaluated by RF and tensile performances after wet-dry conditioning. The detailed conclusions are summarized as follows.

1. The density and compressive strength of HS-ECC decrease with the increase of CR1 proportion. Particularly, CR2-0.4 using smaller CR particle exhibits a higher compressive strength while a lower density than that of CR1-0.4 with a larger CR particle size and can be classified as a lightweight cementitious composite.

2. All the HS-ECC specimens exhibit obvious strain-hardening performance under uniaxial tension. The peak tensile stress and initial tensile stress of HS-ECC decrease as the proportion of CR increases (i.e., $a / b$ from 0.2 to 0.6 ). Nevertheless, the peak tensile strength of HS-ECC with finer CR2 substitution generates a comparable peak tensile strength with the control specimen using SS as a fine aggregate. Besides, the influence of CR substitution and proportion on the tensile strain capacity of HS-ECC is irrelevant. Moreover, HS-ECC with CR substitution indicates a gentler descending branch and a better energy consumption capacity after crack localization.

3. CR acting as artificial flaws can reduce the HS-ECC matrix fracture toughness, activate more microcracks, and reduce crack widths, benefitting the self-healing potential of HS-ECC. Particularly, CR2-0.4 with the smallest crack width of $59 \mu \mathrm{m}$

\section{REFERENCES}

Adesina, A., and Das, S. (2021). Performance of Engineered Cementitious Composites Incorporating Crumb Rubber as Aggregate. Construction Building Mater. 274, 122033. doi:10.1016/j.conbuildmat.2020.122033

Aldea, C.-M., Song, W.-J., Popovics, J. S., and Shah, S. P. (2000). Extent of Healing of Cracked normal Strength concrete. J. Mater. Civ. Eng. 12 (1), 92-96. doi:10.1061/(asce)0899-1561(2000)12:1(92)

American Concrete Institute (2003). ACI Committee Report 213R-03 Structural Lightweight Aggregate concrete. Detroit: American concrete institute.

ASTM (2019). ASTM C215-19, Standard Test Method for Fundamental Transverse, Longitudinal, and Torsional Resonant Frequencies of Concrete Specimens. West Conshohocken, PA: ASTM International.

Cai, Z., Liu, F., Yu, J., Yu, K., and Tian, L. (2021). Development of Ultra-high Ductility Engineered Cementitious Composites as a Novel and Resilient Fireproof Coating. Construction Building Mater. 288, 123090. doi:10.1016/ j.conbuildmat.2021.123090

Chen, Y., Yu, J., and Leung, C. K. Y. (2018). Use of High Strength Strain-Hardening Cementitious Composites for Flexural Repair of concrete Structures with Significant Steel Corrosion. Construction Building Mater. 167, 325-337. doi:10.1016/j.conbuildmat.2018.02.009

Curosu, I., Liebscher, M., Mechtcherine, V., Bellmann, C., and Michel, S. (2017). Tensile Behavior of High-Strength Strain-Hardening Cement-Based Composites (HS-SHCC) Made with High-Performance Polyethylene, corresponding to the peak stress, which is comparable with the value of PVA-ECC, is selected to further study the self-healing properties of HS-ECC.

4. CR2-0.4 specimens have been proven to exhibit effective selfhealing ability from both the mechanical and non-mechanical aspects. The majority of the RF recovery happens before the first 2-5 wet-dry cycles, and the recovery rate for the CR2-0.4 specimens with milder pre-damage is faster than that of those pre-damaged more seriously.

5. All the self-healed CR2-0.4 specimens have strain-hardening behavior with newly formed multi-cracks. The tensile stress-strain curves of the self-healed CR2-0.4 specimens can be divided into four stages according to the significant stiffness differences, representing distinct load transferring mechanisms. The further hydration of binder materials can enhance the interfacial bond stress and thus retain the mechanical performance, especially the tensile strength of the self-healed CR2-0.4 specimens. Further investigation on the self-healing performance of HS-ECC at loading status is warranted.

\section{DATA AVAILABILITY STATEMENT}

The raw data supporting the conclusion of this article will be made available by the authors, without undue reservation.

\section{AUTHOR CONTRIBUTIONS}

YJ: conceptualization and writing of original draft. XQ: methodology. JF: investigation and data curation. YQ: data curation. LM: Investigation and data curation.

Aramid and PBO Fibers. Cement Concrete Res. 98, 71-81. doi:10.1016/ j.cemconres.2017.04.004

Dong, F., Wang, H., Jiang, F., Xing, Q., and Yu, J. (2022). In-Plane Shear Behavior of Masonry Panels Strengthened With Ultra-High Ductile Concrete (UHDC). Eng. Struct. 252, 113609. doi:10.1016/j.engstruct.2021.113609

Edvardsen, C. (1999). "Water Permeability and Autogenous Healing of Cracks in concrete," in Innovation in concrete Structures: Design and Construction (London: Thomas Telford Publishing), 473-487.

Hammond, G. P., and Jones, C. I. (2008). Embodied Energy and Carbon in Construction Materials. Proc. Inst. Civil Eng. - Energ. 161 (2), 87-98. doi:10.1680/ener.2008.161.2.87

Huang, X., Ranade, R., Ni, W., and Li, V. C. (2013). On the Use of Recycled Tire Rubber to Develop Low E-Modulus ECC for Durable concrete Repairs. Construction Building Mater. 46, 134-141. doi:10.1016/j.conbuildmat.2013.04.027

Jacobsen, S., Marchand, J., and Boisvert, L. (1996). Effect of Cracking and Healing on Chloride Transport in OPC concrete. Cement Concrete Res. 26 (6), 869-881. doi:10.1016/0008-8846(96)00072-5

JSCE (2008). Recommendations for Design and Construction of High-Performance Fiber Reinforced Cement Composites with Multiple Fine Cracks. Tokyo, Japan: Japan Society of Civil Engineers, 1-16.

Kan, L.-l., and Shi, H.-s. (2012). Investigation of Self-Healing Behavior of Engineered Cementitious Composites (ECC) Materials. Construction Building Mater. 29, 348-356. doi:10.1016/j.conbuildmat.2011.10.051

Lei, D.-Y., Guo, L.-P., Chen, B., Curosu, I., and Mechtcherine, V. (2019). The Connection between Microscopic and Macroscopic Properties of Ultra-high 
Strength and Ultra-high Ductility Cementitious Composites (UHS-UHDCC). Composites B: Eng. 164, 144-157. doi:10.1016/j.compositesb.2018.11.062

Li, L., Cai, Z., Yu, K., Zhang, Y. X., and Ding, Y. (2019). Performance-based Design of All-Grade Strain Hardening Cementitious Composites with Compressive Strengths from $40 \mathrm{MPa}$ to $120 \mathrm{MPa}$. Cement and Concrete Composites 97, 202-217. doi:10.1016/j.cemconcomp.2019.01.001

Li, V. C., Bos, F. P., Yu, K., McGee, W., Ng, T. Y., Figueiredo, S. C., et al. (2020). On the Emergence of 3D Printable Engineered, Strain Hardening Cementitious Composites (ECC/SHCC). Cement Concrete Res. 132, 106038. doi:10.1016/ j.cemconres.2020.106038

Li, V. C., and Leung, C. K. Y. (1992). Steady-State and Multiple Cracking of Short Random Fiber Composites. J. Eng. Mech. 118 (11), 2246-2264. doi:10.1061/ (asce)0733-9399(1992)118:11(2246)

Li, V. C., and Wang, S. (2006). Microstructure Variability and Macroscopic Composite Properties of High Performance Fiber Reinforced Cementitious Composites. Probabilistic Eng. Mech. 21 (3), 201-206. doi:10.1016/ j.probengmech.2005.10.008

Lin, Z., and Li, V. C. (1997). Crack Bridging in Fiber Reinforced Cementitious Composites with Slip-Hardening Interfaces. J. Mech. Phys. Sol. 45 (5), 763-787. doi:10.1016/s0022-5096(96)00095-6

Naaman, A. E., and Najm, H. (1991). Bond-slip Mechanisms of Steel Fibers in concrete. Mater. J. 88 (2), 135-145.

Oikonomou, N., and Mavridou, S. (2009). Improvement of Chloride Ion Penetration Resistance in Cement Mortars Modified with Rubber from Worn Automobile Tires. Cement and Concrete Composites 31 (6), 403-407. doi:10.1016/j.cemconcomp.2009.04.004

Ranade, R., Li, V. C., Stults, M. D., Heard, W. F., and Rushing, T. S. (2013). Composite Properties of High-Strength, High-Ductility Concrete. ACI Mater. J. 110 (4), 413-422. doi:10.1016/j.optmat.2013.06.025

Reinhardt, H.-W., and Jooss, M. (2003). Permeability and Self-Healing of Cracked concrete as a Function of Temperature and Crack Width. Cement concrete Res. 33 (7), 981-985. doi:10.1016/s0008-8846(02)01099-2

Wang, J., Guo, Z., Yuan, Q., Zhang, P., and Fang, H. (2020). Effects of Ages on the ITZ Microstructure of Crumb Rubber concrete. Construction Building Mater. 254, 119329. doi:10.1016/j.conbuildmat.2020.119329

Yang, Y., Lepech, M. D., Yang, E.-H., and Li, V. C. (2009). Autogenous Healing of Engineered Cementitious Composites under Wet-Dry Cycles. Cement Concrete Res. 39 (5), 382-390. doi:10.1016/j.cemconres.2009.01.013

Yu, K.-Q., Lu, Z.-D., Dai, J.-G., and Shah, S. P. (2020). Direct Tensile Properties and Stress-Strain Model of UHP-ECC. J. Mater. Civ. Eng. 32 (1), 04019334. doi:10.1061/(asce)mt.1943-5533.0002975

Yu, K.-Q., Yu, J.-T., Dai, J.-G., Lu, Z.-D., and Shah, S. P. (2018). Development of Ultra-high Performance Engineered Cementitious Composites Using Polyethylene (PE) Fibers. Construction Building Mater. 158, 217-227. doi:10.1016/j.conbuildmat.2017.10.040

Yu, K., Ding, Y., Liu, J., and Bai, Y. (2020). Energy Dissipation Characteristics of All-Grade Polyethylene Fiber-Reinforced Engineered Cementitious Composites (PE-ECC). Cement and Concrete Composites 106, 103459. doi:10.1016/j.cemconcomp.2019.103459
Yu, K., Mcgee, W., Ng, T. Y., Zhu, H., and Li, V. C. (2021). 3D-printable Engineered Cementitious Composites (3DP-ECC): Fresh and Hardened Properties. Cement Concrete Res. 143, 106388. doi:10.1016/j.cemconres.2021.106388

Yu, K., Wang, Y., Yu, J., and Xu, S. (2017). A Strain-Hardening Cementitious Composites with the Tensile Capacity up to 8. Construction Building Mater. 137, 410-419.

Zhang, Z., Ma, H., and Qian, S. (2015). Investigation on Properties of ECC Incorporating Crumb Rubber of Different Sizes. Act 13 (5), 241-251. doi:10.3151/jact.13.241

Zhang, Z., Qian, S., and Ma, H. (2014). Investigating Mechanical Properties and Self-Healing Behavior of Micro-cracked ECC with Different Volume of Fly Ash. Construction Building Mater. 52, 17-23. doi:10.1016/j.conbuildmat.2013.11.001

Zhang, Z., Yang, F., Liu, J., and Wang, S. P. (2020a). Eco-Friendly High Strength, High Ductility Engineered Cementitious Composites (ECC) With Substitution of Fly ash by Rice Husk Ash. Cem. Concr. Res. 137, 106200.

Zhang, Z., Qin, F., Ma, H., and Xu, L. (2020b). Tailoring an Impact Resistant Engineered Cementitious Composite (ECC) by Incorporation of Crumb Rubber. Construction Building Mater. 262, 120116. doi:10.1016/j.conbuildmat.2020.120116

Zhang, Z., Liu, S., Yang, F., Weng, Y., and Qian, S. Z. (2021). Sustainable High Strength, High Ductility Engineered Cementitious Composites (ECC) With Substitution of Cement by Rice Husk Ash. J. Cleaner Prod. 317, 128379. doi:10.1016/j.jclepro.2021.128379

Zhang, Z., and Zhang, Q. (2017). Self-healing Ability of Engineered Cementitious Composites (ECC) under Different Exposure Environments. Construction Building Mater. 156, 142-151. doi:10.1016/j.conbuildmat.2017.08.166

Zhu, H., Wan, K. T., Satekenova, E., Zhang, D., Leung, C. K. Y., and Kim, J. (2018). Development of Lightweight Strain Hardening Cementitious Composite for Structural Retrofit and Energy Efficiency Improvement of Unreinforced Masonry Housings. Construction Building Mater. 167, 791-812. doi:10.1016/j.conbuildmat.2018.02.033

Conflict of Interest: YQ was employed by the company Qinghai Transportation Planning and Design Research Institute Co., Ltd. LM was employed by Shanghai Tiangu Housing Inspection Company, Ltd.

The remaining authors declare that the research was conducted in the absence of any commercial or financial relationships that could be construed as a potential conflict of interest.

Publisher's Note: All claims expressed in this article are solely those of the authors and do not necessarily represent those of their affiliated organizations, or those of the publisher, the editors, and the reviewers. Any product that may be evaluated in this article, or claim that may be made by its manufacturer, is not guaranteed or endorsed by the publisher.

Copyright $\odot 2021$ Jiangtao, Fangming, Qiong, Qi and Mi. This is an open-access article distributed under the terms of the Creative Commons Attribution License (CC $B Y)$. The use, distribution or reproduction in other forums is permitted, provided the original author(s) and the copyright owner(s) are credited and that the original publication in this journal is cited, in accordance with accepted academic practice. No use, distribution or reproduction is permitted which does not comply with these terms. 